\title{
Variation In Faecal Stanol Concentrations In Neotropical Lakes And Implications For Ancient Maya Population History
} YVES GELINAS ${ }^{2}$, ANDREW BRECKENRIDGE ${ }^{3}$, KEVIN JOHNSTON $^{*}$

'McGill University, Montréal, QC H3A 0E8, Canada

(*correspondence: benjamin.keenan@mail.mcgill.ca)

2Concordia University, Montréal, QC H4B 2A7, Canada

${ }^{3}$ University of Wisconsin-Superior, Superior, WI 54880, USA

Independent Scholar, Columbus, OH 43214, USA

The analysis of faecal stanols in lake sediment cores offer a novel opportunity to reconstruct human population change in the past, assuming that sedimentary faecal stanol concentrations can be accurately related to human population. The ancient Lowland Maya civilization of Central America represents an important ancient society where demographic change remains highly uncertain and contested. In this study we present faecal stanol concentrations in lake surface sediments from lakes across climatic and land-use gradients in Guatemala, Belize, and the Yucatan Peninsula of Mexico to constrain societal and biogeochemical drivers of stanol concentrations in sediments, including proximity to population centres and lake salinity. We then use these insights to interpret the faecal stanol record in a sediment core retrieved from a lagoon adjacent to the archaeological site of Itzan, an ancient population centre in the south-west of the Maya Lowlands. The faecal stanol record from Laguna Itzan implies highly dynamic millennial and centennial scale changes in human populations from 3300 years BP to the present. The variability in faecal stanol concentrations and ratios coincides broadly with patterns of large-scale societal change across the Maya Lowlands, but also implies an earlier presence of humans at this site than is documented by archaeological evidence. The stanol data also indicates frequent centennial scale variability in human populations, especially during the Maya Preclassic period. Our work shows that faecal stanols have a strong potential as proxies for changes in human population and land-use change through time in tropical regions, and can be used to complement archaeological datasets to link human populations with palaeoenvironmental change. 